\title{
Childbirth and Postpartum Period Fear and the Related Factors in Pregnancy
}

\author{
Hamide Zengin1, Icten Olgu Bafali2, Sinem Yalnizoglu Caka33, Oznur Tiryaki1 and Nursan Cinar³ \\ IDepartment of Nutritional Nursing, Bozüyük State Hospital, Bilecik, Turkey \\ ${ }^{2}$ Department of Gynecology and Obstetrics, Haseki Training and Research Hospital, Istanbul, Turkey \\ ${ }^{3}$ Department of Pediatric Nursing, Faculty of Health Science, Sakarya University, Sakarya, Turkey
}

\begin{abstract}
Objective: This study was carried out to determine the factors affecting pregnant women's anxiety levels during delivery and the postpartum period.

Study Design: A descriptive and analytical study.

Place and Duration of Study: Department of Gynecology and Obstetrics, Polyclinic; and Antenetal Education Class, Sakarya University Education and Research Hospital, Sakarya,Turkey, from October 2018 to January 2019.

Methodology: Five hundred pregnant women constituted the sample. The data were obtained by using the questionnaire form consisting 25 questions containing the introductory information of pregnant women, prepared by the researchers, and the fear of childbirth and postpartum period scale (FCPPS). Pregnant women's demographic and obstetrical factors and FCPS score were analysed.

Results: A statistically significant difference was determined between pregnant women's employment status $(p=0.003)$, smoking status $(p<0.001)$, trimester of pregnancy $(p<0.001)$, number of living children $(p=0.015)$, chronic disease $(p<0.001)$, status of receiving education during pregnancy $(p<0.001)$, status of receiving support during/after delivery $(p<0.001)$, and the FCPPS averages.

Conclusion: It was determined that pregnant women's anxieties about delivery and babycare increased, especially in the last trimester.
\end{abstract}

Key Words: Fear of childbirth, Postpartum period, Delivery, Pregnant, Anxiety.

How to cite this article: Zengin $\mathrm{H}$, Bafali IO, Caka SY, Tiryaki O, Cinar N. Childbirth and postpartum period fear and the related factors in pregnancy. J Coll Physicians Surg Pak 2020; 30(2):144-148.

\section{INTRODUCTION}

Pregnancy, which is a period during which psychological, biological and emotional changes occur in women, constitutes one of the most important variables of women's lives. Pregnancy causes some psychological changes such as introversion, worry, uncertainty, anxiety and contradiction.1,2 Although the delivery and postpartum period is a pleasing and exciting process, the psychological and physical problems that occur during this period may lead to life-threatening risks; and consequently may cause the sense of anxiety in women.2,3 Therefore, the sense of anxiety causes women to undergo a difficult delivery and postpartum period. ${ }^{4}$ Anxiety is a type of fear which is ambiguous and felt without perceiving what the problem is. While fear is a situation involving immediate responses, anxiety occurs by feeling the risk situations that may occur in the future. While the sense of anxiety ensures that the

Correspondence to: Sinem Yalnizoglu Caka, Department of Pediatric Nursing, Faculty of Health Sciences, Sakarya University, Sakarya, Turkey

E-mail: sinemyalnizoglu@sakarya.edu.tr

Received: May 22, 2019; Revised: October 20, 2019,

Accepted: December 27, 2019 individual is better motivated when it is at a certain level, it negatively affects the lives of people when it is more than the average level. Pregnant women feel an anxiety that leads to an intense feeling that a potential danger may occur in the labour and postpartum period. 2,5

While pregnant women have worry and anxiety since they don't have enough information about what is going to happen or what happened during labour, and/or cannot comprehend it, delivery anxieties rise to the highest level in the $3^{\text {rd }}$ trimester.4,6 Primiparous pregnant women usually have a fear of uncertainty about what will happen in the future, while multiparous pregnant women have a fear that some conditions may go bad during pregnancy. ${ }^{7}$ Some pregnant women are anxious due to childcare and childrearing for the postpartum period and the changes that may occur in family roles. ${ }^{8}$ Therefore, the causes of anxiety that occur in pregnant women and their levels of anxiety during pregnancy periods vary.

In recent years, an increasing number of systematic compilings have focused on the negative effects of birth fear during and after birth.9,10 In a study, postpartum outcomes of birth fear were examined and the relationship between high-level prenatal fear and postpartum mood disorders was emphasised. ${ }^{11}$ In addition, fear of birth 
may adversely affect the mother-infant relationship, 12 short term and long term baby's growth, especially in the first postpartum period. 13 As for the intrapartum results, many studies have shown that fear of birth predicts a negative birth experience. ${ }^{14,15}$ Although the negative consequences of fear of childbirth have been examined, comprehensive studies examining the associated factors that may cause anxiety in women during and after birth are limited. Therefore, the objective of this study was to determine the factors affecting pregnant women's anxiety levels during delivery and the postpartum period.

\section{METHODOLOGY}

This descriptive and analytical study was conducted in the Department of Gynecology and Obstetrics, Polyclinic; and Antenatal Education Class, Sakarya University Education and Research Hospital, Sakarya, Turkey, from October 2018 to January 2019, after approval from Sakarya University Scientific Research Ethics Committee (Approval number: 71522473/050.01.04/312); and the necessary permissions from the hospitals where the study was carried out were obtained before the study.

All pregnant women, who applied to the Department of Gynecology and Obstetrics Polyclinic or/and Antenatal Education Class (pregnant women who participated in the antenatal education class were applied a questionnaire form before education or during the first application) between October 2018 - January 2019 constituted the population of the study; and 500 pregnant women who met the inclusion criteria constituted the sample. The inclusion criteria were pregnant women applied to the Department of Gynecology and Obstetrics Polyclinic; and Pregnancy School within the time of study, at least primary school graduates, had no risky pregnancy (such as preeclampsia, eclampsia, and threatened preterm labor) and agreed to participate in the study. Pregnant women who were 18 years or younger, who did not agree to participate in the study, who filled the forms incomplete, and who had a risk for pregnancy or fetus, were excluded from the study.

The data were obtained by using the questionnaire form consisting 25 questions, containing the socio-demographic and the obstetric characteristics of pregnant women, prepared by the researchers, and the fear of childbirth and postpartum period scale (FCPPS) developed by Kitapçioglu et al. ${ }^{16}$

All analyses were analysed in the computer environment using the SPSS Statistical Package 22.0. Compliance with normality was evaluated by Kolmogorov-Smirnov test. Number, percentage and Median (IQR) were used as descriptive statistics. Mann-Whitney U-Test was used in paired groups and Kruskal Wallis-H test was used in more than two groups in data without normal distribution. The data are presented as frequencies and percentages for categorical variables. P-values $<0.05$ were considered statistically significant.

\section{RESULTS}

The average age of pregnant women $(\mathrm{N}=500)$ who participated in the study was $28.94 \pm 5.50$ years. Out of the pregnant women, $42.8 \% \quad(n=214)$ were in the age range of 30 years and above, $87.8 \%(n=439)$ had a nuclear family type, 59.8\% ( $n=299)$ were high school graduates, $73 \% \quad(n=365)$ were unemployed, $81.2 \%$ $(n=406)$ were non-smokers, $82.8 \%(n=414)$ were in the third trimester of pregnancy, $70 \%(n=350)$ had a planned pregnancy and $57.6 \%(n=288)$ were multiparous. It was determined that $92 \%(n=460)$ of the participants did not have a chronic disease, $12 \%(n=60)$ of them received education during pregnancy and $92 \%(n=460)$ of them stated that they would receive support during delivery and the postpartum period.

Table I: Comparison of the averages of fear of childbirth and postpartum period scale according to some variables $(n=500)$.

\begin{tabular}{|c|c|c|c|}
\hline Variables & $\mathrm{N}(\%)$ & $\begin{array}{c}\text { FCPPS } \\
\text { Median [IQR] }\end{array}$ & test $/ p$ \\
\hline \multicolumn{4}{|l|}{ Age (years) } \\
\hline $18-23$ & $89(17.8)$ & $6.84[4.71-8.60]$ & KW: 3.260 \\
\hline $24-29$ & $197(39.4)$ & $7.53[5.14-8.69]$ & .196 \\
\hline 30 years and above & $214(42.8)$ & 7.94 [5.48-8.67] & \\
\hline \multicolumn{4}{|l|}{ Family type } \\
\hline Nuclear family & $439(87.8)$ & 7.67 [5.19-8.65] & Z: -.319 \\
\hline Extended family & $61(12.2)$ & $6.83[5.13-8.87]$ & .750 \\
\hline \multicolumn{4}{|l|}{ Education } \\
\hline Primary school & $50(10.0)$ & $6.01[5.30-8.33]$ & KW: 5.049 \\
\hline High-school & $299(59.8)$ & $7.98[5.20-8.74]$ & .080 \\
\hline University and above & $151(30.2)$ & $7.29[5.14-8.53]$ & \\
\hline \multicolumn{4}{|l|}{ Employment status } \\
\hline Employed & $135(27.0)$ & $8.34[5.77-8.78]$ & Z: -3.004 \\
\hline Unemployed & $365(73.0)$ & $6.91[5.10-8.62]$ & $003^{* *}$ \\
\hline \multicolumn{4}{|l|}{ Smoking } \\
\hline Yes & $94(18.8)$ & $8.47[7.17-8.85]$ & Z: -4.576 \\
\hline No & $406(81.2)$ & $6.91[5.09-8.57]$ & $.000^{* *}$ \\
\hline \multicolumn{4}{|l|}{ Pregnancy trimesters } \\
\hline $1^{\text {st }}$ and $2^{\text {nd }}$ trimesters & $86(17.2)$ & $5.04[3.81-5.77]$ & Z: -9.525 \\
\hline 3rd trimester & $414(82.8)$ & $8.15[5.77-8.76]$ & $.000^{* *}$ \\
\hline \multicolumn{4}{|l|}{ Planning of pregnancy } \\
\hline Planned & $350(70.0)$ & $7.81[5.18-8.70]$ & Z: -.939 \\
\hline Unplanned & $150(30.0)$ & 7.08 [5.18-8.54] & .348 \\
\hline \multicolumn{4}{|l|}{ Parity } \\
\hline Nulliparity & $212(42.4)$ & $7.93[5.42-8.76]$ & Z: -2.442 \\
\hline Multiparity & $288(57.6)$ & $7.21[5.09-8.56]$ & $.015^{*}$ \\
\hline \multicolumn{4}{|l|}{ Chronic disease condition } \\
\hline Yes & $40(8.0)$ & $5.39[4.28-6.74]$ & Z:-3.980 \\
\hline No & $460(92.0)$ & $7.81[5.34-8.70]$ & $.000^{\star *}$ \\
\hline \multicolumn{4}{|l|}{ Education in pregnancy } \\
\hline Yes & $60(12.0)$ & $5.54[4.11-8.11]$ & $Z:-3.702$ \\
\hline No & $440(88.0)$ & $7.86[5.41-8.70]$ & $.000^{\star *}$ \\
\hline \multicolumn{4}{|c|}{ Pregnancy and postpartum support } \\
\hline Yes & $460(92.0)$ & $7.86[5.38-8.70]$ & Z:-4.834 \\
\hline No & $40(8.0)$ & $5.14[4.02-7.37]$ & $.000^{\star *}$ \\
\hline
\end{tabular}


Table II: Comparison of pregnant women's employment status and the averages of FCPPS sub-gimensions $(\mathrm{n}=500)$.

\begin{tabular}{|c|c|c|c|c|c|c|c|c|c|}
\hline \multirow[t]{2}{*}{ FCPPS sub-dimentions } & \multicolumn{2}{|c|}{ Employement status } & \multirow[b]{2}{*}{$\begin{array}{l}Z \\
P\end{array}$} & \multicolumn{2}{|c|}{ Pregnancy trimesters } & \multirow[b]{2}{*}{$\begin{array}{l}Z \\
P\end{array}$} & \multicolumn{2}{|c|}{ Parity } & \multirow[b]{2}{*}{$\begin{array}{l}Z \\
P\end{array}$} \\
\hline & $\begin{array}{c}\text { Employed } \\
(\mathrm{n}=135) \\
\text { Median [IQR] }\end{array}$ & $\begin{array}{l}\text { Unemployed } \\
(n=365) \\
\text { Median [IQR] }\end{array}$ & & $\begin{array}{l}1^{\text {st }} \text { and } 2^{\text {nd }} \\
\text { trimesters } \\
(n=365)\end{array}$ & $\begin{array}{c}\text { 3rd trimester } \\
(n=414) \\
\text { Median [IQR] }\end{array}$ & & $\begin{array}{c}\text { Nulliparity } \\
(n=212) \\
\text { Median [IQR] }\end{array}$ & $\begin{array}{c}\text { Multiparity } \\
(n=288) \\
\text { Median [IQR] }\end{array}$ & \\
\hline Anxieties about the baby & $8.00[5.80-9.00]$ & $6.80[4.20-8.60]$ & $-3.653 .000^{\star \star}$ & 3.70 [2.80-5.25] & $8.00[5.60-8.80]$ & $-9.752 .000^{* *}$ & $7.70[4.80-8.80]$ & 7.20 [4.40-8.60] & -1.617.106 \\
\hline Anxieties about labor & $8.00[6.00-8.77]$ & 7.54 [5.15-8.61] & $-2.149 .032^{*}$ & 5.08 [3.54-6.50] & $8.00[6.27-8.77]$ & $-8.323 .000^{* \star}$ & $7.84[6.15-8.77]$ & 7.54 [4.81-8.61] & $-2.154 .031^{*}$ \\
\hline $\begin{array}{l}\text { Anxieties about post- } \\
\text { partum breastfeeding }\end{array}$ & $8.00[6.40-9.20]$ & $7.60[5.60-8.80]$ & -1.587 .113 & 5.60 [3.60-6.90] & $8.00[6.40-9.20]$ & $-7.403 .000^{* *}$ & $8.00[6.00-8.80]$ & $8.00[5.60-8.80]$ & -.588 .556 \\
\hline $\begin{array}{l}\text { Anxiety about insufficiency } \\
\text { in postpartum baby care }\end{array}$ & $8.00[5.14-8.86]$ & $6.28[4.00-8.75]$ & $-2.778 .005^{\star \star}$ & $4.00[2.57-5.43]$ & $7.71[5.07-8.86]$ & $-8,631.000^{* *}$ & $7.71[5.14-8.86]$ & $6.28[3.71-8.57]$ & $-3.778 .000^{* *}$ \\
\hline $\begin{array}{l}\text { Anxieties about social life } \\
\text { after childbirth }\end{array}$ & $8.00[5.50-9.00]$ & $7.00[4.00-8.75]$ & $-2.652 .008^{* *}$ & $4.00[2.00-6.00]$ & $8.00[5.50-9.00]$ & $-8.527 .000^{* *}$ & $8.00[4.12-9.00]$ & $7.00[4.00-8.50]$ & $-2.107 .035^{*}$ \\
\hline $\begin{array}{l}\text { Anxieties about health of } \\
\text { baby and puerperium after } \\
\text { childbirth }\end{array}$ & $7.50[5.75-8.75]$ & $7.00[5.12-8.75]$ & -1.367 .172 & $4.50[3.50-5.81]$ & $7.75[6.00-9.00]$ & $-9.416 .000^{* *}$ & $7.50[5.50-8.75]$ & $6.87[5.06-8.50]$ & -1.446 .148 \\
\hline $\begin{array}{l}\text { Anxiety about not being } \\
\text { able to receive support } \\
\text { from husband after } \\
\text { childbirth }\end{array}$ & $8.00[4.80-9.20]$ & $6.00[3.20-8.80]$ & $-4.553 .000^{\star \star}$ & 2.80 [2.00-4.00] & $8.00[4.40-9.20]$ & $-9.953 .000^{\star *}$ & $8.00[4.00-8.80]$ & $6.40[3.20-8.80]$ & -1.809 .070 \\
\hline Pre-labour anxieties & 8.00 [6.00-9.33] & 8.00 [4.67-9.33] & $-1.996 .046^{\star}$ & 4.67 [3.33-7.33] & $8.00[6.00-9.33]$ & $-7.048 .000^{\star *}$ & 8.00 [6.00-9.33] & 8.00 [4.67-9.33] & -1.839 .066 \\
\hline $\begin{array}{l}\text { Anxieties about the } \\
\text { behaviours of the healthcare } \\
\text { personnel during childbirth }\end{array}$ & $8.00[6.50-9.50]$ & $8.00[6.00-9.00]$ & -1.500 .134 & 6.00 [4.00-8.00] & 8.00 [6.50-9.50] & $-5.154 .000^{\star \star}$ & $\begin{array}{c}8.00 \\
{[6.00-9.37]}\end{array}$ & $8.00[6.00-9.00]$ & -1.250 .211 \\
\hline $\begin{array}{l}\text { Anxiety about cesarean } \\
\text { delivery }\end{array}$ & $8.00[6.00-10.00]$ & $8.00[5.00-10.00]$ & -1.233 .217 & 5.00 [3.00-8.00] & $8.00[6.00-10.00]$ & $-6.634 .000^{\star *}$ & $\begin{array}{c}8.00 \\
{[6.00-10.00]}\end{array}$ & 8.00 [5.00-10.00] & -1.521.128 \\
\hline
\end{tabular}

$Z=$ Mann-Whitney U-test; ${ }^{*} p<.05,{ }^{* *} p<.001$

The averages of FCPPS were statistically significantly high in those who were employed $(p=0.003)$, smokers $(p<0.001)$, those who were in the third trimester of pregnancy $(p<0.001)$, those who were expecting their first child $(p=0.015)$, those without chronic disease history ( $p<0.001)$, those who did not receive education during pregnancy $(p<0.001)$, and those who were thinking of receiving support during/after delivery $(p<0.001$, Table $\mathrm{I})$. These were also higher in the employed and those in the third trimester.

When pregnant women's parity and the averages obtained from FCPPS sub-dimensions were compared, a statistically significant difference was found between some anxieties about labour's insufficiency in postpartum babycare and social life after childbirth sub-dimensions and the number of living children $(p=0.031, p<0.001$ and $p=0.035$, respectively, Table II).

\section{DISCUSSION}

Fear of birth may negatively affect a woman's psychological condition and birth experience during pregnancy. With respect to this study aiming to examine pregnant women's anxiety levels during delivery and the postpartum period, it was observed that the averages obtained by pregnant women from each subdimension were high. When the results of the study on the subject are examined in the literature, it was found that the anxieties about the behaviours of the healthcare personnel during childbirth, postpartum breastfeeding and labour heads were higher in other studies.1,5,16-18 Although the results of the studies carried out on the subject and the results of this study are generally similar, the averages of anxieties about postpartum breastfeeding, and cesarean delivery were found to be higher compared to the present study. The averages of anxieties about the behaviours of the healthcare personnel during childbirth was also found to be high in studies is worrying in that it indicates that there has been no change in the approach of healthcare personnel in terms of pregnant women during nine years, i.e. period of time between year during which the original scale was prepared and the year of the current study.

There was a statistically significant difference between the averages of FCPPS and some variables. When the literature is examined, it was found that the cases of pregnant women with anxiety and depression increased as age increased, trimester periods progressed and education levels decreased. In addition, it was found that the employment status of pregnant women affected anxiety and depression. ${ }^{18-20}$ The results of the study in the literature showed similarity with this study.

In this study, it was determined that $18.8 \%$ of pregnant women were smokers and that the averages of FCPPS, in other words anxiety levels of smokers were significantly high compared to non-smokers. In the studies carried out in Turkey, the smoking rate of pregnant women during pregnancy ranged from $6.8 \%$ to $28 \% .21$ The result is similar to this study. In addition, in studies that examined the outcomes of smoking in relation to obstetric and newborns during pregnancy, it was found that smoking in pregnancy increased the risk of placental abruption, placenta previa, preeclampsia, low birth weight incidence, preterm birth and the rate of hospitalization in the intensive care unit. 22 Pregnant women are usually aware that smoking during pregnancy leads to negative health outcomes. However, this information often fails to motivate pregnant women to quit smoking. Therefore, reduction of smoking during pregnancy is more probable than completely quitting smoking during pregnancy. ${ }^{23}$

In this study, it was reported that $8 \%$ of pregnant women did not/would not be able to receive support during 
pregnancy and the postpartum period. It was determined that the averages of FCPPS, in other words, anxiety levels of those without support were significantly high compared to those with support. In many studies, insufficient social support and disharmony between spouses are reported to be among the important causes of psychiatric disorders observed in the postpartum period. 24

In this study, it was determined that $12 \%$ of pregnant women received education during pregnancy, $88 \%$ of them did not receive education, and the averages of FCPPS (anxiety levels) of pregnant women who did not receive education were significantly high compared to pregnant women who received education. When the literature is examined, many studies have shown that pregnancy-based preparation, physiotherapy and psychotherapy-based interventions during pregnancy are effective in increasing the satisfaction levels and delivery readiness at birth. 25 The result of our study is similar to the studies carried out.

In a study carried out, it was found that primiparous pregnant women in the $1^{\text {st }}$ and $2^{\text {nd }}$ trimesters with averages of FCPPS with the type of parity in their trimester periods had more anxieties about prenatal, birth process and postnatal processes compared to multiparous pregnant women.18 In the study of Ternström et al.,4 it was stated that pregnant women, especially primiparous pregnant women, have further fear of childbirth due to fear of pain, welfare of the baby, fear of physical damage to themselves or their babies, and ignorance of their rights in the community where they live compared to multiparous pregnant women. In the study of Körükcü et al. ${ }^{3}$ no relationship was found between pregnant women's levels of fear of childbirth and parity type. 3 The results of our study were found to be similar to the studies carried out earlier.

\section{CONCLUSION}

As a result of the study, it was found that anxiety levels of pregnant women were generally high according to pregnancy periods. It was determined that those who were employed, smokers, primiparous, those without chronic disease, those who did not receive education during pregnancy, and would not be able to receive support during pregnancy, had higher levels of anxiety. Moreover, pregnant women's anxieties about delivery and babycare increased, especially in the last trimester. The research findings and other studies in this field indicate the presence of fears or anxieties about pregnancy and childbirth. Based on these results, it can be said that it is important to educate pregnant women about the anxieties in pregnancy and delivery. Nurses and other health workers are recommended to give education on pregnancy and delivery process, as well as preparation for maternity. The most important results of these efforts may be a decrease in cesarean rate and an increase in breastfeeding rate.

\section{ETHICAL APPROVAL:}

Ethical approval from the Sakarya University Scientific Research Ethics Committee was obtained prior to initiation of the research work.

\section{PATIENTS' CONSENT:}

All participants were informed that the data related to this research would be used only for publication.

\section{CONFLICT OF INTEREST:}

Authors declared no conflict of interest.

\section{AUTHORS' CONTRIBUTION:}

HZ, IOB, NÇ: Study design.

$\mathrm{HZ}$, SYÇ, ÖT: Data collection and/or processing, analysis and/or interpretation.

HZ, IOB, SYÇ, ÖT, NÇ: Preparation of the manuscript, critical review and/or revision.

\section{REFERENCES}

1. Üst Z, Pasinlioglu T. Determination of anxieties related to delivery and postpartum period in primiparous and multiparous pregnant women. Saglik Bilimleri ve Meslekleri Dergisi 2015; 2:306-17.

2. Cetisli NE, Zirek ZD, Abali FB. Childbirth and postpartum period fear in pregnant women and the affecting factors. Aquichan 2016; 16:32-42.

3. Korukcu O, Deliktas A, Aydin R, Kabukcuoglu K. Investigation of the relationship between the psychosocial health status and fear of childbirth in healthy pregnancies. Clin Exp Health Sci 2017; 7:152-8.

4. Ternström E, Hildingsson I, Haines H, Rubertsson C. Higher prevalence of childbirth related fear in foreign born pregnant women: Findings from a community sample in Sweden. Midwifery 2015; 31:445-50.

5. Köse S, Pasinlioglu T. The effects of birth and postpartum education given to pregnant women on mitigating anxiety concerning these periods. Uluslararasi Hakemli Kadin Hastaliklari Ve Anne Çocuk Saglligi Dergisi 2015; 2:49-63.

6. Handelzalts JE, Becker G, Ahren MP, Lurie S, Raz N, Tamir Z, et al. Personality fear of childbirth and birth outcomes in nulliparous women. Arch Gynecol Obstet 2015; 291:1055-62.

7. Stoll K, Hauck Y, Downe S, Edmonds J, Gross MM, Malott A, et al. Cross-cultural development and psychometric evaluation of a measure to assess fear of childbirth prior to pregnancy. Sex Reprod Healthc 2016; 8:49-54.

8. Beydag KD. Adaptation to motherhood in the postpartum period and the nurse's role. TSK Koruyucu Hekimlik Bülteni 2007; 6:479-84.

9. Molgora S, Fenaroli V, Cracolici E, Saita E. Antenatal fear of childbirth and emergency cesarean section delivery: A systematic narrative review. J Reprod Infant Psychol 2019; 38:1-19.

10. Dencker A, Nilsson C, Begley C, Jangsten E, Mollberg M, Patel H, et al. Causes and outcomes in studies of fear of childbirth: A systematic review. Women Birth 2019; 32:99-111. 
11. Poggi L, Goutaudier N, Séjourné N, Chabrol H. When fear of childbirth is pathological, the fear continuum. Matern Child Health J 2018; 22:772-8.

12. Klabbers GA, Wijma K, van Bakel HJA, Paarlberg KM, Vingerhoets AJJM. Resistance to fear of childbirth and stability of mother-child bond. Early Child Dev Care 2018; 553:1-10.

13. Ryding EL, Wijma B, Wijma K, Rydhstrom H. Fear of childbirth during pregnancy may increase the risk of emergency caesarean section. Acta Obstet Gynecol Scand 1998; 77:542-7.

14. Fenaroli V, Saita E, Molgora S, Accordini M. Italian women's childbirth: A prospective longitudinal study of delivery predictors and subjective experience. J Reprod Infant Psychol 2016; 34: 235-46.

15. Takegata M, Haruna M, Matsuzaki M, Shiraishi M, Okano T, Severinsson E. Does antenatal fear of childbirth predict postnatal fear of childbirth? a study of japanese women. Open Journal of Nurs 2015; 5:144-52.

16. Kitapçioglu G, Yanikkerem E, Sevil Ü, Yüksel D. Fear of childbirth and the postpartum period: A scale development and validation study. Adnan Menderes Üniversitesi Tip Fakültesi Dergisi 2008; 9:47-54.

17. Blackmore ER, Gustafsson H, Gilchrist M, Wyman C, O'Connor TG. Pregnancy-related anxiety evidence of distinct clinical significance from a prospective longitudinal study. J Affect Disord 2016; 197:251-8.

18. Küçükkaya B, Dindar I, Erçel Ö, Yilmaz E. Anxieties of pregnant women related to delivery and postpartum period during gestational periods. JAREN 2018; 4:28-36.

19. Khashan AS, Everard C, McCowan LME, Dekker G, MossMorris R, Baker PN, et al. Second-trimester maternal distress increases the risk of small for gestational age. Psychol Med 2014; 44:2799-10.

20. Kapan M, Yanikkerem E. Partner violence depression and loneliness in pregnant women living in rural and urban areas. TAF Preve Med Bull 2016; 15:431-9.

21. Balkaya NA, Vural G, Eroglu K. Investigating problems related to the health of mothers and their babies resulting from risk factors determined during pregnancy. Düzce Üniversitesi Sagluk Bilimleri Enstitüsü Dergisi 2014; 1:6-16.

22. Shobeiri F, Jenabi E. Smoking and placenta previa: A metaanalysis. J Matern Fetal Neonat Med 2017; 30:2985-90.

23. Berlin I, Golmard JL, Jacob N, Tanguy ML, Heishman SJ. Cigarette smoking during pregnancy: Do complete abstinence and low level cigarette smoking have similar impact on birth weight? Nicotine Tob Res 2017; 19:518-24.

24. Okanli A, Tortumluoglu G, Kirpinar I. The relationship between pregnant women perceived social support from family and problem solving skill. Anadolu Psikiyatri dergisi 2003; 4:98-105.

25. Mete S, Çiçek Ö, Alus-Tokat M, Çamlibel M, Uludag E. The effect of childbirth preparation classes on fear of childbirth preference and preparation of labor. Turkiye Klinikleri $J$ Nurs Sci 2017; 9:201-6. …ㄷ…. 